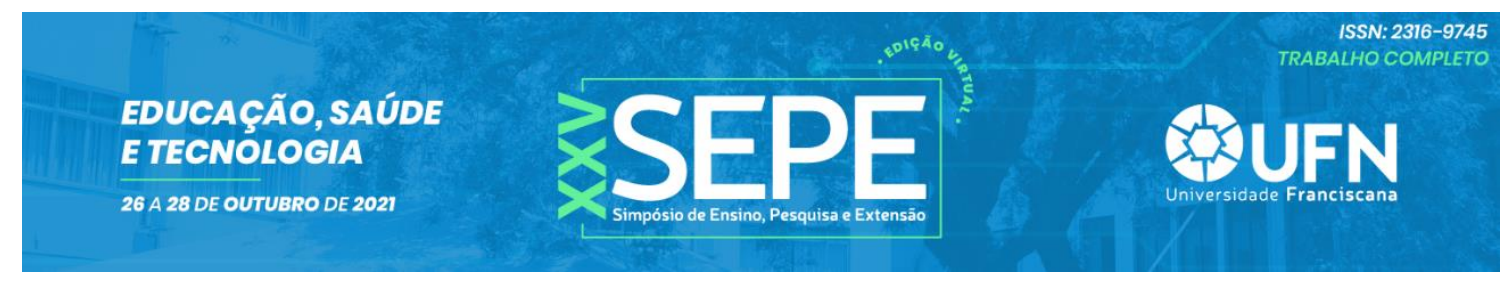

http://doi.org/10.48195/sepe2021-054

\title{
ABORTOS PROVOCADOS NO BRASIL: COMO DIMINUIR ESTA PRÁTICA?
}

Bruno Bohrer Flores ${ }^{1}$; Natielen Jacques Schuch²

\section{RESUMO}

O aborto provocado é um assunto debatido mundialmente, sobretudo nos países onde ele é considerado crime, como é o caso do Brasil. É considerado um problema de saúde pública, tanto pela magnitude como pela persistência. O objetivo desta revisão bibliográfica é identificar a relevância do estudo do tema sobre o aborto provocado no Brasil assim como identificar medidas de saúde pública capazes de diminuir a incidência do aborto provocado. Como metodologia foi realizada revisão bibliográfica, utilizando artigos indexados nas bases de dados PubMed, Scielo e Google Acadêmico. Os resultados dos estudos evidenciaram que no Brasil a cada cinco mulheres grávidas, uma foi submetida a aborto provocado, demostrando uma elevada prevalência da prática. Como conclusão, entende-se que a implementação de programas de planejamento familiar efetivos no controle de natalidade evitando assim gestações não planejadas, possa ser uma maneira para diminuir de forma efetiva a permanência de abortos provocados no Brasil.

Palavras-chave: Aborto; Gestação; Planejamento familiar

Eixo Temático: Atenção Integral e Promoção à Saúde (AIPS).

\section{INTRODUÇÃO}

O aborto provocado é um assunto debatido mundialmente, sobretudo nos países onde ele é considerado crime, como é o caso do Brasil. Caracterizado pela interrupção voluntária da gestação, a prática consiste em impedir o desenvolvimento do embrião ou induzir a eliminação do feto, podendo ser provocado ou induzido. (SANTOS et al, 2012).

Segundo um estudo com base em estimativas da Organização Mundial da Saúde (OMS), aproximadamente 55 milhões de abortos ocorreram entre 2010 e 2014 no

1. Bruno Bohrer Flores, Mestrando e Professor da Universidade Franciscana. E-mail: brunobohrerflores@ hotmail.com

2. Natielen Jacques Schuch, Orientadora e Docente do Curso de Mestrado em Ciências da Saúde e da Vida da Universidade Franciscana. E-mail: natielen@ufn.edu.br 
mundo, sendo $45 \%$ destes considerados abortos inseguros, estando África, Ásia e América Latina concentrando 97\% deste percentual (GANATRA, et al, 2014).

A OMS define aborto inseguro como um procedimento para o término da gestação, realizado por pessoas sem a habilidade necessária ou em um ambiente sem padronização para a realização de procedimentos médicos, ou a conjunção dos dois fatores, o que leva a um aumento da morbidade e mortalidade relacionada a prática e custos ao sistema de saúde. (SAY, 2014).

No Brasil, o aborto é um problema de saúde pública, tanto pela magnitude como pela persistência (DINIZ, 2017), e por tal motivo, devemos avaliar medidas que sejam capazes e eficazes na diminuição desta prática.

O objetivo desta revisão bibliográfica é identificar a relevância do estudo do tema sobre o aborto provocado no Brasil assim como identificar medidas de saúde pública capazes de diminuir a incidência do aborto provocado.

\section{MÉTODOS}

A presente pesquisa é constituída de uma revisão integrativa da literatura referente ao estudo do tema sobre o aborto provocado no Brasil e identificação de medidas de saúde pública capazes de diminuir a incidência do aborto provocado. Segundo Whittemore e Knafl (2005), uma revisão integrativa é uma ferramenta que compila diversas metodologias de pesquisa experimental e não experimental, tendo um papel importante maior na prática baseada em evidências clínica. Assim, para a realização desta revisão bibliográfica, foram utilizados artigos indexados nas bases de dados PubMed, Scielo e Google Acadêmico, com assunto vinculado a revisão proposta. Como critérios de inclusão, os artigos relevantes foram selecionados com as seguintes palavras-chave: "Aborto", Gestação", Planejamento Familiar".

O procedimento de busca desenvolveu-se no mês de setembro de 2021, tendo por base artigos nas línguas portuguesa, inglesa e espanhola publicados entre 2010 e 2021 desde que disponíveis na íntegra. Foram excluídos os artigos publicados fora do recorte temporal estabelecido, duplicados em mais de uma base de pesquisa, teses,

1. Bruno Bohrer Flores, Mestrando e Professor da Universidade Franciscana. E-mail: brunobohrerflores@ hotmail.com

2. Natielen Jacques Schuch, Orientadora e Docente do Curso de Mestrado em Ciências da Saúde e da Vida da Universidade Franciscana. E-mail: natielen@ufn.edu.br 
dissertações, artigos de revisão, protocolos, recomendações e artigos não disponíveis na íntegra.

\section{RESULTADOS E DISCUSSÃO}

O aborto induzido é um tema polêmico que envolve questões religiosas, culturais e políticas. No Brasil, a permissão da prática da interrupção da gestação voluntária acontece em caso de estupro ou risco de vida materna. As demais situações são consideradas ilegais e por tal motivo a real magnitude do abortamento inseguro não é conhecida com exatidão (CÚNICO et al, 2014). Situações incompatíveis com a vida extrauterina, tais como presença de acrania e anencefalia, permitem que o aborto possa ser realizado no país apenas após autorização judicial (MARANHA, 2012).

De acordo com a Pesquisa Nacional de Aborto (PNA), estimasse que em 2015 ocorreu meio milhão de abortos no Brasil e no ano de 2016 quase 1 a cada 5 mulheres com até 40 anos havia realizado pelo menos um aborto, o que evidencia um fenômeno frequente e persistente no nosso país, sendo assim um dos maiores problemas de saúde pública na qual devemos enfrentar (DINIZ, 2017).

Realizado de forma insegura, em contextos de ilegalidade, o aborto resulta em graves consequências para a sociedade, pois afeta a saúde da mulher, com elevada morbidade e mortalidade e também sobrecarrega o sistema de saúde, implicando em custos e reduzindo a produtividade do mesmo.

As novas responsabilidades atribuídas as mulheres como a sua inserção no trabalho fora do lar, passaram a competir com a maternidade. A presença de uma gestação indesejada ou inoportuna limita a mulher contemporânea de aproveitamento completo de desenvolvimento pessoal, e dificulta o ingresso no mercado de trabalho, principalmente quando comparado aos homens, e por este novo contexto do papel da mulher na sociedade, a presença de uma gestação não planejada pode ser vista de forma catastrófica (MANENTE, 2016).

Considerada um problema de saúde pública, a gestação não planejada acarreta um risco adicional no número de abortos, sendo desta forma um importante indicador da falha no controle do processo reprodutivo (DELGADO, 2020).

1. Bruno Bohrer Flores, Mestrando e Professor da Universidade Franciscana. E-mail: brunobohrerflores@hotmail.com

2. Natielen Jacques Schuch, Orientadora e Docente do Curso de Mestrado em Ciências da Saúde e da Vida da Universidade Franciscana. E-mail: natielen@ufn.edu.br 
No Brasil, o aborto é considerado uma das quatro causas de mortes maternas evitáveis, ocorrendo principalmente em casos onde não houve um planejamento reprodutivo por parte do casal. De acordo com a Organização Mundial da Saúde, 31\% das gestações no país terminam em aborto (DOMINGOS, 2010) e são registradas cerca de 230 mil internações todo ano para o tratamento das complicações decorrentes da prática, sendo a curetagem pós-abortamento o segundo procedimento obstétrico mais realizado nos serviços públicos de saúde (GALI, VIANA, 2010).

Um estudo da Universidade Federal do Rio de Janeiro, com o objetivo de identificar a prevalência de gestação não planejada revelou que quase a metade das mulheres cadastradas nas equipes da Estratégia Saúde da Família não conseguiram ter acesso ao seu método anticoncepcional nas farmácias das Unidades Básicas de Saúde, o que comprometeu 0 planejamento reprodutivo das participantes (EVANGELISTA,2015).

Embora haja uma da lei de Planejamento Familiar que prevê a oferta de um amplo leque de contraceptivos e uma política governamental relacionada a anticoncepção, a má qualidade da atenção dos serviços fazem com que a gestação não planejada no Brasil seja uma realidade a ser enfrentada (EVANGELISTA,2015).

\section{CONCLUSÃO}

A prática do aborto induzido ainda é uma realidade no nosso país, acarretando um problema de saúde pública, tanto pela magnitude como pela persistência, gerando custos ao sistema de saúde, morbidade e mortalidade as mulheres que realizam esta prática. A implementação de programas de planejamento familiar efetivas no controle de natalidade, evitando assim gestações não planejadas, são medidas que podem diminuir de forma efetiva a permanência de abortos provocados no Brasil. É importante estarmos cientes que o problema desta temática não é em si o aborto e sim a gestação não planejada. A diminuição das taxas da gestação não planejada, com uma abordagem em especial em mulheres vulneráveis a mesma, parece ser a medida mais eficaz para assim diminuirmos a incidência do aborto no nosso país.

1. Bruno Bohrer Flores, Mestrando e Professor da Universidade Franciscana. E-mail: brunobohrerflores@ hotmail.com

2. Natielen Jacques Schuch, Orientadora e Docente do Curso de Mestrado em Ciências da Saúde e da Vida da Universidade Franciscana. E-mail: natielen@ufn.edu.br 


\section{REFERÊNCIAS}

CHALEM, E. et al. Gravidez na adolescência: perfil sócio demográfico e comportamental de uma população da periferia de São Paulo, Brasil. Cad. Saúde Pública, v.23, n1, p.177-186, 2007.

CÚNICO, S. et al. Algumas considerações acerca da legalização do aborto no Brasil. Mudanças-Psicologia da Saúde, 2004.

Diniz D, Medeiros M, Madeiro A. Pesquisa Nacional de Aborto. Ciência Saúde Coletiva, v.2, n2, p.653-660, 2017.

Domingos, Selisvane Ribeiro da Fonseca; Merigui, Miriam Aparecida Barbosa. O aborto como causa de mortalidade materna: um pensar para o cuidado de enfermagem. Esc Anna Nery, v. 14, n. 1, p. 177-81, 2010.

Evangelista CB, Barbieri M, Silva PLNJ. Gravidez não planejada e fatores associados à participação em programa de planejamento familiar. Revista de Pesquisa e Cuidado Fundamental Online, v.7, n.2, p.2464-2474, 2015.

Gali MB, Viana APAL. O impacto da ilegalidade do aborto na saúde das mulheres e nos serviços de saúde em cinco estados brasileiros: subsídios para o debate político. Fazendo Gênero 9. Diáspora, Diversidades, 2010.

GANATRA, B. et al. From concept to measurement: operationalizing WHO's definition of unsafe abortion. Bull World Health Organ, v.92, n.3, p. 155, 2014.

MANENTE, Milena Valelongo; RODRIGUES, Olga Maria Piazentin Rolim. Maternidade e Trabalho: Associação entre Depressão Pós-parto, Apoio Social e Satisfação Conjugal. Periódicos Eletrônicos em Psicologia., Porto Alegre , v. 20, n. 1, p. 99-111, jul. 2016.

MARANHA, Luana Antunes et al. Acrania e outras falhas na formação dos ossos do crânio. JBNC-JORNAL BRASILEIRO DE NEUROCIRURGIA, v. 23, n. 3, p. 217-221, 2012.

SANTOS. et al. Prevalência e características de mulheres com aborto provocado -

Revista Brasileira de Epidemiologia, v.15, n.1, p 123-133, 2012.

1. Bruno Bohrer Flores, Mestrando e Professor da Universidade Franciscana. E-mail: brunobohrerflores@ hotmail.com

2. Natielen Jacques Schuch, Orientadora e Docente do Curso de Mestrado em Ciências da Saúde e da Vida da Universidade Franciscana. E-mail: natielen@ufn.edu.br 
SAY, L. et al. Global causes of maternal death: a WHO systematic analysis. Lancet Glob Health, v2, n6, p323-333, 2014.

1. Bruno Bohrer Flores, Mestrando e Professor da Universidade Franciscana. E-mail: brunobohrerflores@hotmail.com

2. Natielen Jacques Schuch, Orientadora e Docente do Curso de Mestrado em Ciências da Saúde e da Vida da Universidade Franciscana. E-mail: natielen@ufn.edu.br 